\title{
Use of Science and Technology in Solving Social Problems at Smart City: Safety Improvement of Pedestrian Crosswalk Using a Water Screen
}

\author{
Hong Joo Lee \\ Department of Industrial \& Management Engineering, Kyonggi University \\ 154-42 Gwanggyosan-ro, Yeongtong-gu, Suwon, Kyonggi-do, Republic of Korea \\ blue1024@kyonggi.ac.kr
}

\begin{abstract}
This paper reviews previous studies analyzing recent traffic accident frequencies and types to develop an effective system designed to resolve traffic accidents, which comprise a significant social issue. Towards this end, this study developed a crosswalk safety system designed to boost the safety of pedestrian crosswalks, using the IT-based water screen.
\end{abstract}

Keywords: Water screen, Crosswalk Safety System, Social Problem, Social Technology

\section{Introduction}

In 2012, 4,743 pedestrians were killed in traffic crashes in the United States, and another 76,000 pedestrians were injured. This averages to one crash-related pedestrian death every 2 hours, and a pedestrian injury every 7 minutes [1]. Besides, The 2011 OECD report on pedestrian traffic accident deaths by nation revealed that South Korea's pedestrian traffic accident death rate was $39.1 \%$, which is twice the average OECD rate of 18.8\%. Table 1 shows pedestrian traffic accident deaths rates in OECD Nations. And Table 2 has analysis of pedestrian traffic accidents by type. According to data of Seoul city [2], pedestrian crosswalk accidents account for the highest percentage, and there were more nighttime accident deaths than daytime accident deaths.

Table 1. Pedestrian Traffic Accident Death Rates in OECD Member Countries

\begin{tabular}{|c|c|c|c|}
\hline Nation & Percentage & Nation & Percentage \\
\hline $\begin{array}{c}\text { Korea } \\
\text { (Republic of) }\end{array}$ & $39.1 \%$ & Luxemburg & $18.2 \%$ \\
\hline Japan & $36.1 \%$ & Austria & $16.6 \%$ \\
\hline Israel & $33.7 \%$ & Sweden & $16.6 \%$ \\
\hline Poland & $33.6 \%$ & Germany & $15.3 \%$ \\
\hline Iceland & $33.3 \%$ & Italy & $15.3 \%$ \\
\hline U.K & $23.8 \%$ & Denmark & $15.0 \%$ \\
\hline Czech & $22.8 \%$ & Slovenia & $14.9 \%$ \\
\hline Portugal & $22.3 \%$ & Australia & $14.5 \%$ \\
\hline
\end{tabular}

Received (June 18, 2017), Review Result (August 24, 2017), Accepted (September 5, 2017) 


\begin{tabular}{|c|c|c|c|}
\hline Switzerland & $21.6 \%$ & Finland & $14.0 \%$ \\
\hline Greece & $19.5 \%$ & USA & $13.7 \%$ \\
\hline Hungary & $19.4 \%$ & France & $13.1 \%$ \\
\hline Spain & $18.4 \%$ & Belgium & $12.9 \%$ \\
\hline \multicolumn{4}{|c}{ (Source: Seoul City) }
\end{tabular}

An analysis of pedestrian traffic accident deaths by type found that crosswalk deaths account for the largest portion. Also, nighttime pedestrian traffic accidents are more frequent than daytime pedestrian traffic accidents. According to a study by Ko (2015), in the case of accidents, $49.4 \%$ of traffic accidents occurred at night and $57.6 \%$ of all deaths occurred at night. In crosswalks where traffic lights were installed, the nighttime accident rate was $52 \%$ higher than that of non-signal pedestrian crossings. A driver's failure to signal at crosswalks was also analyzed as a main factor for traffic accidents. In addition, since it is not easy for a driver to spot pedestrians at night when compared to the daytime, vehicle speed is relatively high at the time of accidents, which increases the probability a fatal accident. The mortality rate was found to be 1.4 times higher than that of 3.3 persons [3]. The accidents were attributed to pedestrians' jaywalking, breach of traffic signals, and over speeding.

Table 2. Analysis of Pedestrian Traffic Accidents by Types

\begin{tabular}{|c|c|}
\hline Pedestrian traffic accidents by type & Persons \\
\hline While walking on crosswalks & 112 \\
\hline while walking on roadways & 17 \\
\hline while walking on the edge of roads & 2 \\
\hline while walking on walkways & 10 \\
\hline others & 74 \\
\hline
\end{tabular}

(Source: Seoul City)

Thus, to reduce crosswalk danger rates, diverse types of sophisticated crosswalk facilities have been installed and operated, but their safety and efficiency have yet to be verified. Furthermore, detailed regulations on the installation of such facilities have yet to be established. Against such a backdrop, this paper analyzed the problems surrounding the existing crosswalk traffic accidents to address the said problems. In particular, nighttime traffic accidents are attributed to the driver's difficulty in securing safety in road structures and supplementary facilities, driver fatigue, inappropriate street lamps and disharmony among all these factors. It cannot be denied that nighttime traffic accidents cause greater damage than daytime traffic accidents. Thus, to reduce nighttime traffic accidents and deaths, comparison of general traffic accident prevention measures with entirely different methods is required. Thus, measures for the prevention of traffic accidents, considering the unique nighttime conditions, should be established and implemented. To resolve such problems, this paper researched on a pedestrian safety crosswalk system using the new water screen technology. 


\section{Literature Review}

\subsection{Research about Road Safety}

According to the manual for the safety of pedestrians and roads presented by WHO (2013), it has been proposed that a safety system for pedestrians on the road should be equipped to provide a safe environment from traffic accidents [4]. In particular, in order to reduce the speed of the vehicle, it was necessary to clearly display the pedestrian crossing and to warn in advance that sufficient warning was required [4].

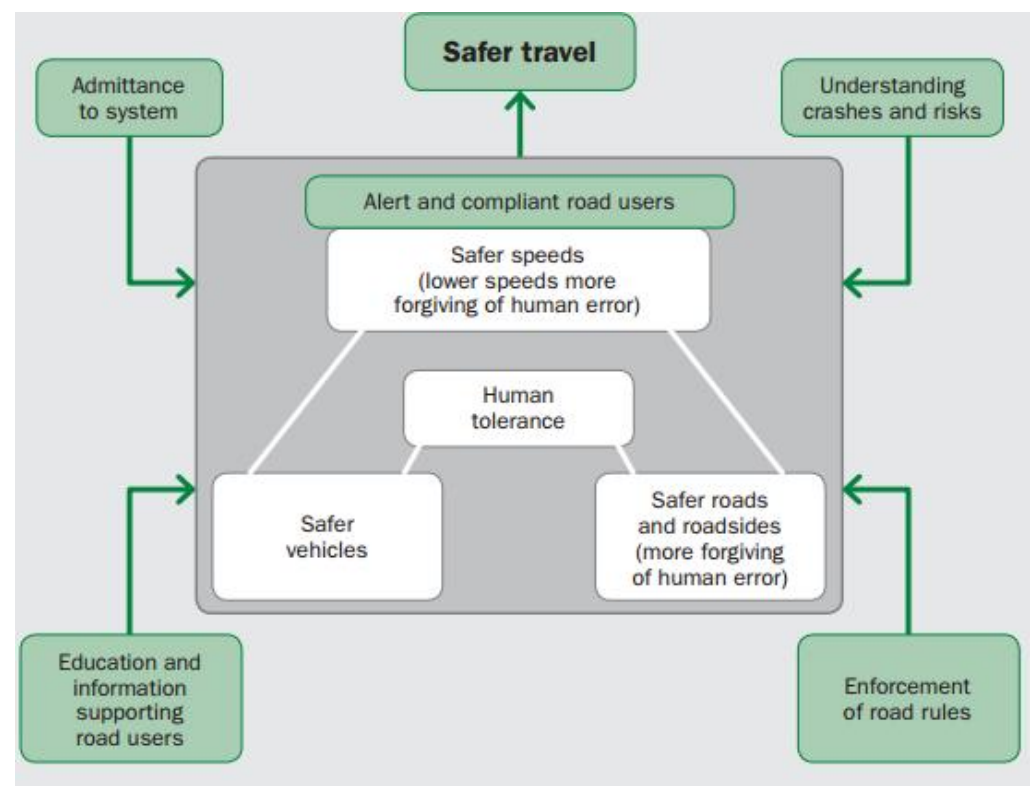

(Source: World Health Organization, 2013)

Figure 1. Safe System Approach

Remote, rural roads, compared with urban roads, have less traffic but oftentimes see vehicles travel and run at high speeds. This difference is significant between roads with less traffic and urban roads.

Vehicles running on such remote, quiet roads may have no continuous lightinginstalled sections leading to poor visibility, challenging the driver's patience for unnecessarily waiting for the go sign, provoking the driver to violate traffic rules, and thus cause pedestrian deaths. Since these roads frequently cause pedestrian traffic accidents, fresh traffic safety methods and technologies should be secured, instead of adhering to the perfunctory lightings that shine the crosswalks [5].

Drivers decide their driving speeds after considering diverse factors, including the physical road conditions, traffic situations, their vehicle performance, speed limits and crackdown intensity, and passage value. Such decisions are a crucial factor that directly influences vehicle clearance and traffic safety problems.

Furthermore, developed countries perceive vehicle speeds as the crucial cause of traffic accidents, and look positively for diverse solutions for the management of vehicle speeds. In particular, nighttime crosswalk accidents are significantly attributed to vehicle over speeding and the driver's negligence. Thus, there is a need to research methods intended for perceiving pedestrians' movement and for reducing vehicle speeds. According to 1997 U.S. Department of Transportation data, over 30\% of fatal traffic accidents are attributed to over speeding beyond the prescribed speed limit, and various studies on the relationship between vehicle speeds and fatality are mentioned [6].

Also, studies on pedestrian accidents revealed that, at a vehicle speed of under $20 \mathrm{mph}$, the death rate was under $5 \%$, while $30 \mathrm{mph}$ it was $45 \%$, and $80 \%$ at $40 \mathrm{mph}$, raising the 
pedestrian fatality rate heavily. For this reason, nations are endeavoring to work out measures to reduce vehicle speeds, and to prevent vehicle over speeding to reduce traffic accident damages.

Regarding the driver's own choice of speed, many researchers explain it in terms of the relationship between the surrounding environment and the driver's perceived danger levels. In particular, pedestrian crossings should provide a device that reduces vehicle speed and improves visibility so pedestrians can see the driver well. In fact, Australia reported a 59\% decrease in pedestrian collision after the improvement of this system [4].

Table 3. Nighttime Traffic Accidents by Cause

\begin{tabular}{|c|c|c|c|c|c|c|}
\hline \multirow{2}{*}{ Category } & \multicolumn{2}{|c|}{$\begin{array}{c}\text { Before the intensive } \\
\text { installation of lightings }\end{array}$} & \multicolumn{2}{|c|}{$\begin{array}{c}\text { After the intensive } \\
\text { installation of lightings }\end{array}$} & \multicolumn{2}{|c|}{ Change (\%) } \\
\cline { 2 - 7 } & Total & Night & Total & Day & Total & Night \\
\hline $\begin{array}{c}\text { Crosswalk } \\
\text { pedestrian } \\
\text { accidents }\end{array}$ & 32 & 26 & 30 & 12 & -6.25 & \begin{tabular}{c}
- \\
\hline
\end{tabular}
\end{tabular}

(Source: Park, 2007)

Also, to identify the effects of crosswalk signs on vehicle speeds, FHWA analyzed the vehicle speed before and after the markings of crosswalks, revealing that crosswalk markings alone did not significantly reduce vehicle speed [8]. An analysis of the previous studies revealed that, in order to most effectively lower the nighttime pedestrian accident rate, lighting systems, etc. should be installed to boost driving visibility.

\subsection{Speed Decision Factors}

Taylor studied the relationship between the driver's own perceived danger level and travel speed, and thus announced a risk speed model by which the driver's own perception of danger is the important factor for adjusting his travel speeds, and by which the driver adjusts the speed so as to maintain the danger level during travel [9]. Also, Van der Horst (1998) explained the process of the driver choosing his vehicle speeds as in [Figure 2].

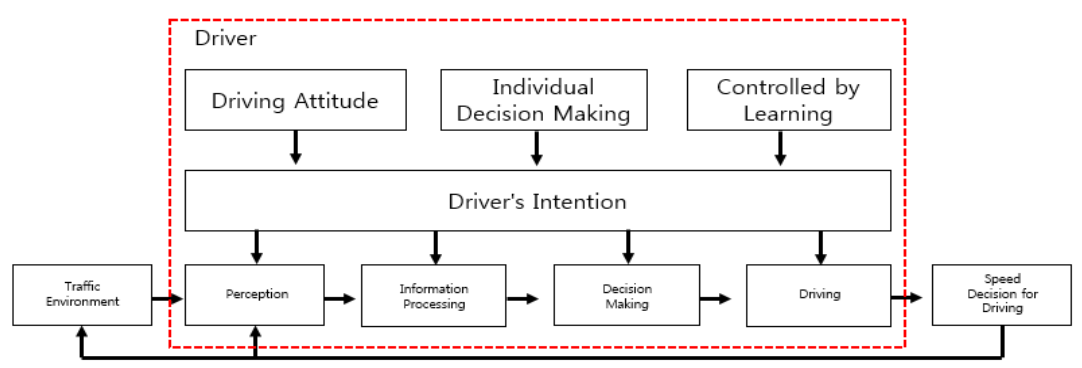

\section{Figure 2. Internal and External Speed-Decision Factors and the Process of Choosing Speeds}

He saw that the driver's road situation perception ability can influence his driving behavior, and proved that enhancing the driver's perception ability can reduce his vehicle speed at crosswalks [10]. Park (2007), using traffic accident data, researched on the effects of crosswalk lightings before and after installation. He revealed that nighttime traffic accidents were reduced by $24.2 \%$ after the installation of crosswalk lightings [7]. Park Tae-Hoon (2007) also reported in his research that, when lightings were intensively 
installed at the crosswalk, the nighttime pedestrian accidents could be reduced by about $53 \%[11]$.

\section{Strategy for Problem Solving}

If a driver or a pedestrian is given unilateral access, such as vehicle protection or pedestrian protection on a pedestrian crossing at a traffic light, the pedestrian is not allowed to cross. Thus, improving the environment is the most important [3].

For this purpose, information on walking time is provided. In places where there is little traffic at midnight and where unauthorized crossing is continuously occurring, the blinking signal can be activated to enhance the driver's responsibility and attract attention [3].

When pedestrians are protected, the installation of Traffic Surveillance Camera is expanded to comply with driver signals. In Germany and Australia, when the road speed limit is above a certain level, the pedestrian crossing is restricted. Inevitably, when the pedestrian crossing is installed at a high speed of $45 \mathrm{mph}$ or more, it is preferable to install a buffer zone of the same size [3].
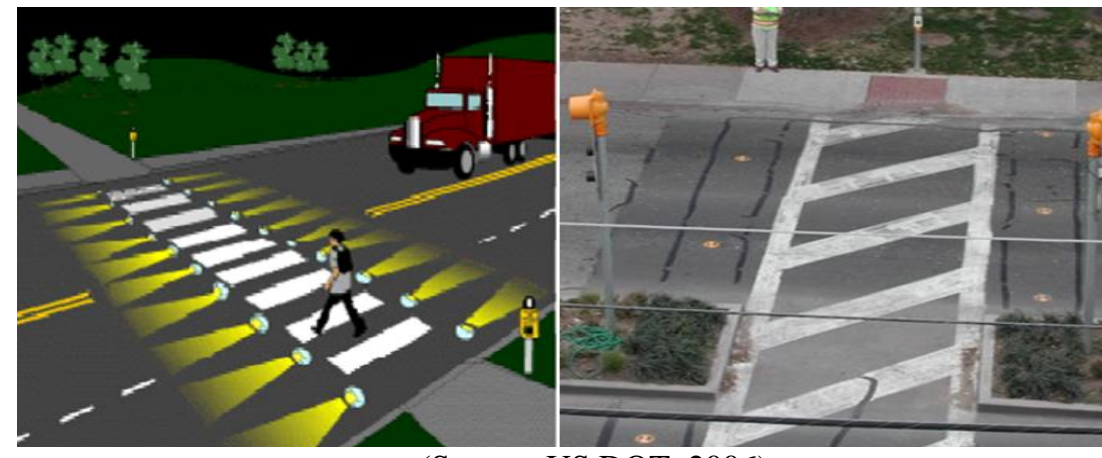

(Source: US DOT, 2006)

Figure 3. Working Example of In-Roadway Warning Lights with Pedestrian Pushbutton in Austin, Texas

Figure 3 shows an example of a pedestrian safety system presented by the US Department of Transportation [12]. In this study, based on the previous research, the countermeasures for problem solving are summarized as follows.

Table 4. Solution for Traffic Accident Problems

\begin{tabular}{|c|c|c|}
\hline $\begin{array}{c}\text { Cause of traffic } \\
\text { accident }\end{array}$ & Response strategy & Countermeasure \\
\hline $\begin{array}{l}\text { Signal Violation of } \\
\text { Driving }\end{array}$ & $\begin{array}{c}\text { Driving traffic, Reducing } \\
\text { speed } \\
\text { Pedestrian crossing / } \\
\text { Pedestrian visibility } \\
\text { reinforcement }\end{array}$ & $\begin{array}{c}\text { Pedestrian crosswalk speed limit } \\
\text { regulation, } \\
\text { Multi-purpose speed camera } \\
\text { installation, } \\
\text { Compliance of pedestrian } \\
\text { crosswalk lighting }\end{array}$ \\
\hline Driver's carelessness & $\begin{array}{c}\text { Driving traffic, Reducing } \\
\text { speed }\end{array}$ & Display of speed reduction \\
\hline $\begin{array}{c}\text { Crosswalk visibility } \\
\text { problem }\end{array}$ & $\begin{array}{l}\text { Reinforcement visibility } \\
\text { of pedestrian crossing, } \\
\text { Reducing driving speed }\end{array}$ & $\begin{array}{c}\text { Compliance of pedestrian } \\
\text { crosswalk lighting, } \\
\text { In-Street Pedestrian Sign } \\
\text { installation, } \\
\text { High-visible pedestrian crosswalk } \\
\text { installation }\end{array}$ \\
\hline
\end{tabular}




\begin{tabular}{|c|c|c|}
\hline $\begin{array}{c}\text { Pedestrian / vehicle } \\
\text { visibility problem }\end{array}$ & $\begin{array}{c}\text { Reinforcement visibility } \\
\text { of pedestrian crossing, } \\
\text { Reinforcement } \\
\text { pedestrian visibility }\end{array}$ & $\begin{array}{c}\text { Compliance of pedestrian } \\
\text { crosswalk lighting, } \\
\text { Flashing pedestrian cross walking } \\
\text { installation }\end{array}$ \\
\hline
\end{tabular}

\section{Method for Problem Solution: Virtual Police Using Water Screen}

In the section, I proposed the following research proposition through literature reviews

Research Proposition: To increase pedestrian safety at crosswalks, drivers must reduce their driving speed, and a high visibility system should be developed for pedestrians as well

This paper based on such previous studies, a pedestrian safety crosswalk system was developed using the water screen that enables the driver to better perceive crosswalks and to reduce vehicle speed.

\subsection{Safety Improvement of Pedestrian Crosswalk Using a Water Screen}

The water screen uses the light's property of preventing penetration and instead reflecting off the water. In other words, a water screen uses the concept that when light is shined on the flowing water, the light does not pass through it, but is reflected instead. When the water is pumped to a certain level, the water is sprayed. It is a technique to project images. In this study, I developed a solution for problem solving based on the fact that the water screen serves as a large screen and the view ability of the driver is very easy from a far. This can be a very effective system considering the high rate of traffic accidents at night.

In addition, the crosswalk is a place where the vehicle stops and travels repeatedly, and is a place where environmental pollution through tire wear can be caused [13]. Therefore, dust can be expected to be suppressed by spraying water vapor periodically [14].

Thus in the paper, water injection devices have been studied for forming water film on the top and side using the traffic lights on both sides of the crosswalk. For this, in this regard, [Figure 3] presents the proposed water screen.

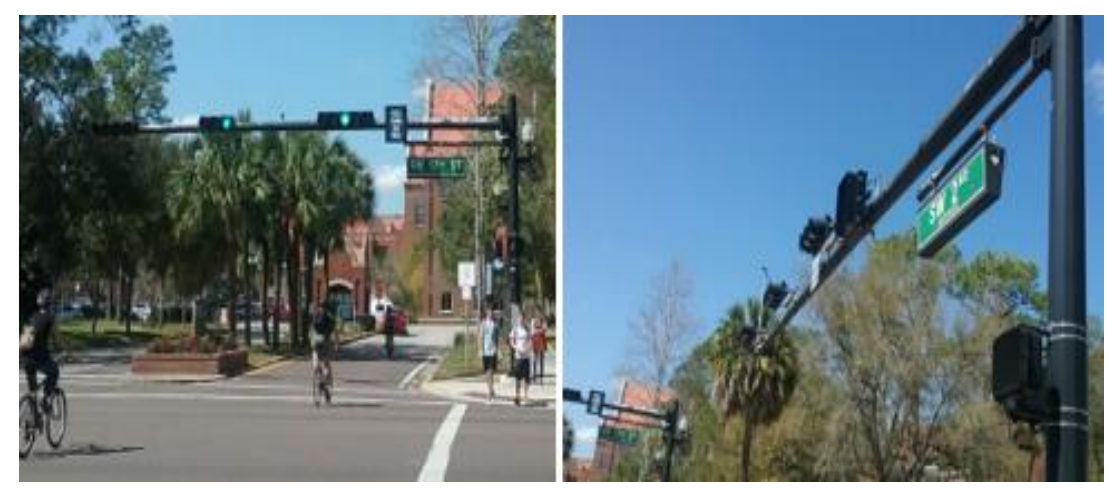

Figure 3. Place of Water Screen Installation 

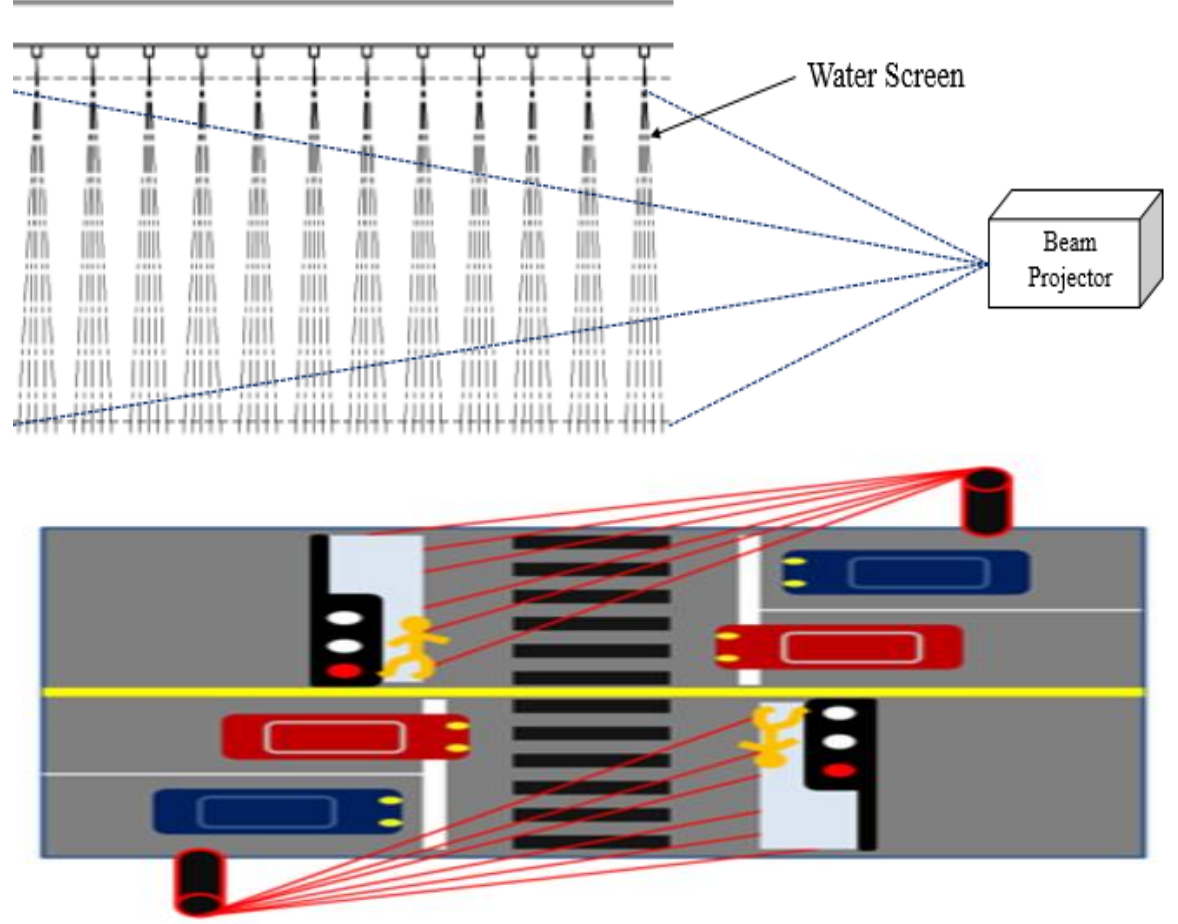

Figure 4. Water Screen Operation Principle and Installation Location

In this study, the water screen is installed in the traffic lights of the crosswalk as shown in Figure 4. As shown in [Figure 5], the water screen is installed behind the crosswalk to present the driver the virtual police image using the water screen. The driver perceives the virtual police image and reduces speed, thereby preventing pedestrian accidents on the road.

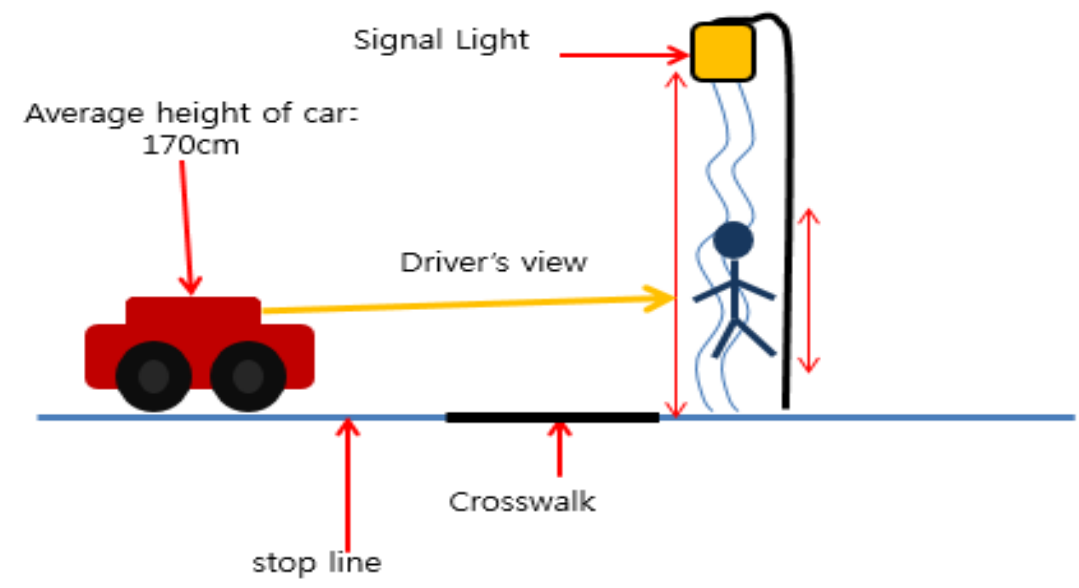

Figure 5. System Design Using the Water Screen

For this purpose, in order to develop a safe pedestrian crossing system through water screen, I first photographed a crossing pedestrian and a virtual police. 


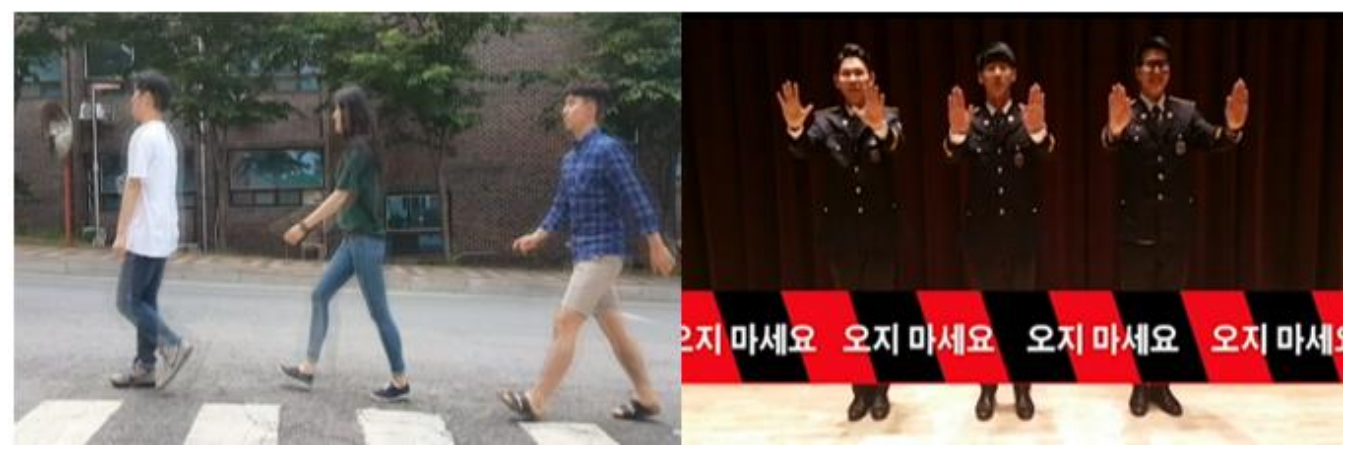

Figure 6. Video Production for Virtual Screen

Based on the system design [Figure 5, 6], the pedestrian safety system [Figure 7] was developed. Specifically, a system was designed and completed by which the pre-crafted crosswalk pedestrian or police officer image is projected onto the water screen, allowing the driver to perceive that image and thus reduce his speed.
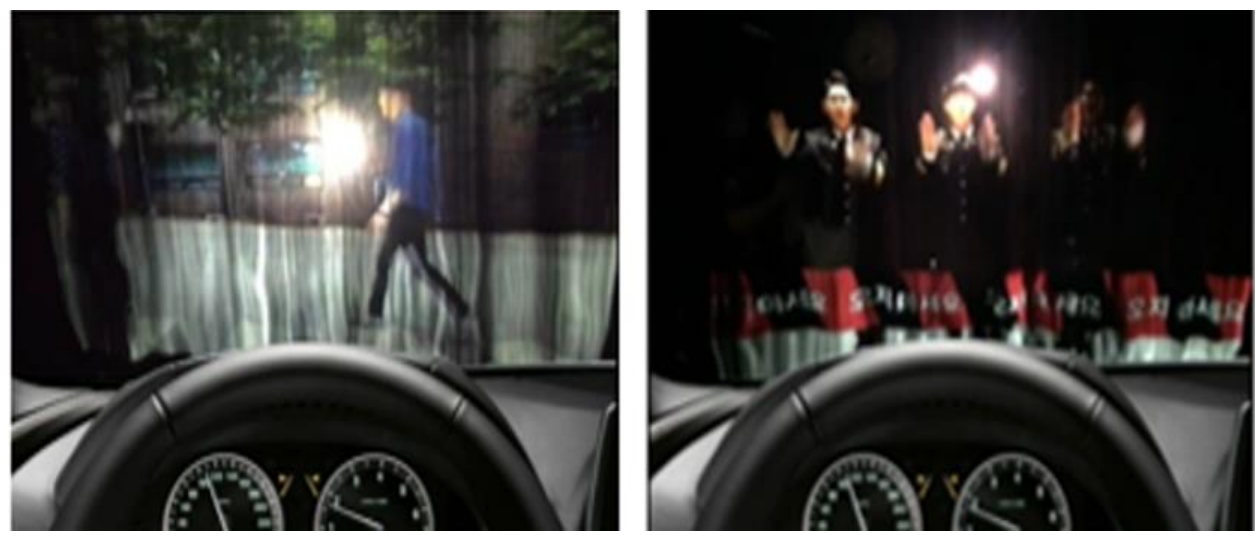

Figure 7. Pedestrian Safety System Using the Water Screen

In addition, based on the completed images, I experimented with the effect of wind and wetting clothes or objects of pedestrians by using water screen equipment operated by National Science Museum. In this experiment, the pedestrian of the pedestrian crossing is considered as a person, and the results from the cognitive point of view are analyzed. To this end, I have test about 20 people in the water screen developed in this study. And I interviewed about the wetness of the clothes due to sprayed water vapor, other inconvenience, and visibility. All respondents to the interview responded that the water screen did not provide any inconvenience to the walking environment.

\section{Research Result}

In this study, various previous studies were analyzed to find solutions to traffic problems. In order to reduce traffic accidents, pedestrians who occupied a large part of traffic accidents were given the suggestion to reduce the speed and develop a system that allows the pedestrian crossing to be visible

In this study, I developed a virtual police using a water screen technology. The system proposed in this study is a method that helps to solve social issues, such as securing the visibility of the driver in the nighttime, tire wear and reducing the dust in the city through science and technology. The purpose of this study is to find effective solutions to social problems by using existing methods rather than advanced technologies. 


\section{Research Limitation and Future Research}

I suggested the system within the paper. However, variables such as fog and other weather conditions may affect this system.

In addition, this study, which is still in the initial stage, needs to install the proposed system on actual roads to continue improve its suitability for the road environment. Also, after constructing the proposed system, its practicality and effectiveness should be tested by comparing actual statistics to determine the rate at which actual pedestrian crosswalk accident rates are reduced.

\section{Acknowledgement}

This work was supported by Kyonggi University Research Grant 2015.

\section{References}

[1] Department of Transportation (US), "National Highway Traffic Safety Administration (NHTSA). Traffic Safety Facts 2012: Pedestrians" Washington (DC): NHTSA, Available from URL: http://wwwnrd.nhtsa.dot.gov/Pubs/811888.pdf, (2012).

[2] Seoul City, "Seoul City Report", Available from URL: https://traffic.seoul.go.kr/archives/19606, (2014).

[3] B. K. Ko, "Pedestrian Accident Types and Characteristics at Crosswalk", Transportation Technology and Policy, vol. 124, no. 4, (2015), pp. 40-47.

[4] World Health Organization, "Pedestrian safety: A road safety manual for decision-makers and practitioners", (2013).

[5] L. S. Ki, "Alternative to Improve the Lighting of Crosswalk on Rural Highways", Journal of The Korea Contents Association, vol. 13, no. 30, (2013), pp. 435-443.

[6] National Highway Traffic Safety Administration, "Traffic Safety Fact Sheet”, U.S.DOT, (1997).

[7] J. C. Park, "Analysis on the effect for prevention facilities on crosswalk accident", Graduate School, Chonnam National University, M.S Thesis, (2007).

[8] FHWA, the Effect of Crosswalk Markings on Vehicle Speeds in Maryland, Virginia, and Arizona, (2000).

[9] D. H. Taylor, "Drivers' galvanic skin response and the risk of accident", Ergonomics, vol. 7, (1964), pp. 439-451.

[10] H. Van der, "Factors Influencing Driver's Speed Behaviour and Adaptation", MASTER working Paper, (1998).

[11] P. T. Hoon, "An Effect of Safety Facilities on Crosswalk Accident", Korean Society of Civil Engineers, (2007), pp. 1559-1562.

[12] Department of Transportation (US), Federal Highway Administration University Course on Bicycle and Pedestrian Transportation, Available from URL: https://www.fhwa.dot.gov/publications/research/safety/pedbike/05085/chapt10.cfm, (2006).

[13] Y. Masakazu and Y. Shohei, "Dust Resulting from Tire Wear and the Risk of Health Hazards", Journal of Environmental Protection, vol. 4, no. 6, (2013), pp. 509-515.

[14] B. C. Andrew, C. V. Jon and D. T. Edward, "Adding Steam To Control Dust in Mineral Processing, Report of Investigations”, United States Department of the Interior, vol. 8935, (1985). 
International Journal of Control and Automation Vol.10, No.9 (2017) 